\title{
Transportation-Driven Mars Surface Operations Supporting an Evolvable Mars Campaign
}

\author{
Larry Toups, larry.toups- \\ $1 @$ @asa.gov \\ NASA Johnson Space Center, NASA \\ Road 1, Houston, TX 77058 \\ Stephen J. Hoffman, PhD, \\ stephen.j.hoffman@nasa.gov \\ Science Applications International, \\ 2450 NASA Parkway, Houston, TX \\ 77058
}

\begin{abstract}
This paper describes the results of a study evaluating options for supporting a series of human missions to a single Mars surface destination. In this scenario the infrastructure emplaced during previous visits to this site is leveraged in following missions. The goal of this single site approach to Mars surface infrastructure is to enable "Steady State" operations by at least 4 crew for up to 500 sols at this site. These characteristics, along with the transportation system used to deliver crew and equipment to and from Mars, are collectively known as the Evolvable Mars Campaign (EMC).

Information in this paper is presented in the sequence in which it was accomplished. First, a logical buildup sequence of surface infrastructure was developed to achieve the desired "Steady State" operations on the Mars surface. This was based on a concept of operations that met objectives of the EMC. Second, infrastructure capabilities were identified to carry out this concept of operations. Third, systems (in the form of conceptual elements) were identified to provide these capabilities. This included top-level mass, power and volume estimates for these elements. Fourth, the results were then used in analyses to evaluate three options (18t, 27t, and 40t landed mass) of Mars Lander delivery capability to the surface. Finally, Mars arrival mass estimates were generated based upon the entry, descent, and landing requirements for inclusion in separate assessments of in-space transportation capabilities for the EMC.
\end{abstract}

\section{TABLE OF CONTENTS}

1. INTRODUCTION .1

2. CONCEPT OF OPERATIONS ................................2

3. CAPABILITIES ...................................................2

4. SEQUENCE OF SURFACE BUILDUP .....................4

5. SYSTEMS AND ELEMENT CONCEPTS ................4

6. RESULTS......................................................10

7. SUMMARY .....................................................13

REFERENCES.....................................................13

BIOGRAPHY .............................................14

U.S. Government work not protected by U.S. copyright

\author{
Kendall Brown, PhD, PE, \\ kendall.brown@nasa.gov \\ NASA Marshall Space Flight Center, \\ Huntsville, Alabama, 35812
}

\section{INTRODUCTION}

For many years NASA has investigated alternative human Mars missions, examining different mission objectives, trajectories, vehicles, and technologies, the combinations of which have often been referred to as reference missions or architectures. The pros and cons exhibited in these different combinations have been noted and documented for future consideration in many sources. But at the highest levels, decisions regarding the timing and objectives for a human mission to Mars continue to evolve while at the lowest levels, relevant technologies continue to advance. This results in an on-going need for assessments of reference mission or architecture options to provide meaningful characterizations to assist those making decisions regarding timing, objectives, and technologies.

This paper discusses the results of one portion of these many assessments - the impact to surface operations resulting from (1) a choice to focus all surface infrastructure for human surface missions at a single site on Mars and (2) the pros and cons of building up this infrastructure using landers with different payload delivery capabilities. The "single site" portion of this assessment can be traced to the on-going evolution of NASA's Evolutionary Mars Campaign (EMC) and the desire to explore different highlevel goals and objectives to help understand the impact of these choices before committing to any of them. The "payload capability" portion of this assessment was carried out to examine several discrete lander sizes that were determined by the mass of certain payload combinations. The payload capacity of the lander is one of the key trades for the EMC: lander payload capacity traded with the number of landers needed to deliver a required surface infrastructure and support "Steady State" operations. A small payload capacity translates into a small lander that can be sent to Mars by a proportionately small launch vehicle and in-space transportation system. The developmental and recurring costs for a small lander and associated transportation system are assumed to be proportionately smaller than a large lander and the transportation system to support it. But assumed "Steady State" operations on Mars defines the total infrastructure required and recurring support in terms of consumables and spare parts. A large lander should be able to establish the surface infrastructure 
and resupply this facility with fewer vehicle, meaning potential savings from economies of scale as well as fewer launches and landing events, decreasing the risk of failure of any one event. Understanding the pros and cons associated with following either of these paths is one of the primary motivations for this assessment.

Over the past four years, NASA has been implementing the NASA Authorization Act of 2010 [1]. The Act calls on NASA to (1) develop and evolve the Space Launch System (SLS) rocket and Orion crew vehicle and (2) to expand human exploration beyond low Earth orbit to cis-lunar space destinations, leading eventually to the international exploration of Mars. To satisfy the second of these actions NASA is defining a long-term, flexible and sustainable deep space exploration architecture termed the "Evolvable Mars Campaign.” In short, the EMC provides a basis for (1) architecture development, and (2) identification and analysis of trade studies with NASA's partners and stakeholders. NASA is structuring the EMC such that it can reasonably adjust to changing priorities across the decades. From this work will emerge the roadmap NASA will follow through cis-lunar space to pioneer Mars.[2]

In work completed during 2014 a set of ground-rules and assumptions were established to examine one particular approach to the human exploration of Mars that would satisfy objectives set out in guiding documents such as the National Space Policy of 2010 [3] and the NASA Authorization Act of 2010. Principle among these groundrules and assumptions that are relevant to the results described in this paper was a choice to concentrate all of the surface assets needed to support human exploration at a single site and then sending all crews to this site for all subsequent missions in the EMC. This contrasts with the scenario considered in Design Reference Architecture 5.0 (DRA 5.0) [4] in which a campaign of three missions sends crews to three separate stand-alone locations on Mars. Two additional key assumptions for this assessment included (1) the inclusion of sufficient infrastructure to support a crew of at least four for a period of up to 500 Sols (one Martian day - slightly more than 24 hours long) on the surface and (2) a first surface mission consisting of a crew of two remaining on the surface for up to 30 Sols as a validation of the landing and ascent elements of the transportation system. The EMC approach assumed here allows surface infrastructure to be built up over a longer period of time compared with DRA 5.0 as well as avoiding replication of these infrastructure assets at three different locations. But this assumed EMC approach would likely not allow crews to explore as diverse a range of surface sites as would be possible in the DRA 5.0 approach. Having results from both of these assessments - the use of a single surface site and the impacts of the lander's payload delivery capability gives decision makers the opportunity to make a reasonable comparison of the relative costs and benefits of each approach.

\section{CONCEPT OF OPERATIONS}

The assumptions mentioned above make up a portion of the concept of operations (ConOps) for the human exploration on the surface of Mars. The more inclusive ConOps defines the principles of operations for surface exploration, from which more detailed operations processes and required functional capabilities can be developed. These principles of operations typically result from identifying significant design-driving operations (i.e., events or activities) and characterizing them to the level of detail necessary to assess design impact. To identify these "significant operations" required a definition of "steady state" operations desired for this particular instance of the EMC. A crew of at least four operating on the surface for up to 500 Sols defines part of this steady state. The remainder of the definition was derived from a substantial amount of work carried out in 2012 and 2013 by the Destination Operations Team (DOT) that was chartered to examine surface operations for a DRA 5.0-like Mars surface exploration scenario in more detail than was possible during the original DRA 5.0 study [4]. None of the other ground rules or assumptions made for this particular instance of the EMC precluded the use of this scenario and the maturity of the assessments conducted by the DOT allowed this assessment to move rapidly to the types of assessments and comparisons desired for this particular instance of the EMC. The following sections will discuss how this ConOps was used to define capabilities of the surface infrastructure and then translate these into representative systems and elements necessary for the detailed assessments.

\section{CApabilities}

To perform tasks and activities consistent with the concept of operations and meet the Goals and Objectives of the EMC, as described in Section 2, the team identified broad capability categories that would be needed. These categories were then used to identify notional elements to provide that capability. The seven capabilities identified were: Habitation, In-Situ Resource Utilization (ISRU), Power, Extravehicular Activity (EVA), Mobility, Robotics, and Science.

The team then identified the extent of the capability required to enable the Mars short stay surface mission of 2 crew for up to 30 Sols, then evolving to the "Steady State" supporting 4 crew for the 500 Sol surface mission. These are summarized in Table 3.1. 
Table 3.1. Capability Required for 2 Crew 30 Sol and 4 Crew 500 Sol Surface Stays

\begin{tabular}{|c|l|l|}
\hline & \multicolumn{1}{|c|}{ Initial Short Stay } & \multicolumn{1}{|c|}{ Steady State } \\
\hline Habitation & $\begin{array}{l}\text { For 2 Crew for up to 30 Sols. } \\
\text { Crew arrives in and lives out of small pressurized rover or } \\
\text { habitation element }\end{array}$ & $\begin{array}{l}\text { For 4 Crew for up to 500 Sols. } \\
\text { A dedicated habitable volume with necessary redundancies }\end{array}$ \\
\hline ISRU & $\begin{array}{l}\text { 27t Lander option - O2 from atmosphere reduces number of } \\
\text { landers required and propellant transfer needs }\end{array}$ & $\begin{array}{l}\text { O2 from Mars atmosphere, growth option could include regolith } \\
\text { ISRU (LOX plus ingredients for CH4) }\end{array}$ \\
\hline Power & $25 \mathrm{kWe}$ for ISRU; 30 kWe continuous deployed & Robust, routine EVA including maintenance of suits \\
\hline EVA & EVA for 5 - 10 crew sorties & $\begin{array}{l}\text { Small unpressurized rover for local traverses. } \\
\text { Small pressurized rovers capable of two week sorties. }\end{array}$ \\
\hline Mobility & $\begin{array}{l}\text { Small pressurized rover (enabling/required for crew delivery to } \\
\text { surface in some scenarios and used as a 30 day habitat) }\end{array}$ & $\begin{array}{l}\text { Capable of reaching 10s to 100s of km from the landing site. } \\
\text { At least one rover to be kept "sterile" to be used in "special } \\
\text { regions" as defined by the Planetary Protection Office } \\
\text { Capability to conduct “real time” surface science }\end{array}$ \\
\hline Robotics & $\begin{array}{l}\text { Robotic partnership to extend the reach beyond what the crew can } \\
\text { accomplish in a short duration mission (potential for crew } \\
\text { teleoperation prior to arrival) }\end{array}$ & \\
\hline Science & Initial equipment as payload mass/volume is available & \\
\hline
\end{tabular}


These capability requirements were then used to identify a notional set of elements that would be delivered to the surface to provide these capabilities in a sequence consistent with the previously discussed ground rules, assumptions, and concept of operation. These notional elements are summarized in Table 3.2. The nominal sequence in which these elements are deployed is discussed next in Section 4 and described in greater detail in Section 5, Systems and Elements Concepts.

Table 3.2. Capability Driven Notional Elements

\begin{tabular}{|c|l|}
\hline \multirow{4}{*}{ Habitation } & Surface Habitation (4/500 day monolithic) \\
\cline { 2 - 2 } & Surface Habitat (4/500 day modular) \\
\cline { 2 - 2 } & Habitation Augmentation \\
\cline { 2 - 2 } & ECLSS/Maintenance Hub \\
\cline { 2 - 2 } & Consumables for up to N Sols \\
\cline { 2 - 2 } & Spares and Logistics \\
\cline { 2 - 2 } & Crew \\
\hline \multirow{5}{*}{ ISRU } & Demonstration Unit (Atmospheric) \\
\cline { 2 - 2 } & Full Scale Unit (Atmospheric) \\
\cline { 2 - 2 } & LOX Tanker \\
\cline { 2 - 2 } & CH4 Tanker \\
\hline \multirow{4}{*}{ Evwer } & Demonstration FSP Unit (kilo-power) \\
\cline { 2 - 2 } & Full Scale Unit (kilo-power) \\
\hline \multirow{2}{*}{ Mobility } & EVA + PLSS \\
\cline { 2 - 2 } & LEA \\
\cline { 2 - 2 } & Logistics \\
\cline { 2 - 2 } & Mobility System to Reposition Payload \\
\cline { 2 - 2 } & Small Unpressurized Rover \\
\cline { 2 - 2 } & Small Pressurized Rover \\
\cline { 2 - 2 } & Spares and Logistics \\
\hline Robotics & Robotic Rover \\
\hline Science & Allocated Payload \\
\cline { 2 - 2 } & Reconfigurable Surface Science Facility \\
\hline Transportation & Mars Ascent Vehicle \\
\hline
\end{tabular}

\section{SEQUENCE OF SURFACE BUILDUP}

The ConOps assumed for this study plus the capabilities just described guides a logical sequence of surface infrastructure buildup and achievement of EMC goals and objectives.

Two aspects of the assumed ConOps are worth reviewing here as they were not discussed in any detail in Section 2. The first is the assumption of in situ resource utilization (ISRU) for surface operations. In general, ISRU can include the use of any locally obtained resources as part of the surface mission. While there is great potential associated with a broad usage of local resources, this study assumes only the use of the Martial atmosphere to produce oxygen for the Mars ascent vehicle (MAV - described in more detail in the next section). Oxygen makes up the largest component of the MAV and other studies have shown that the systems needed to produce it require far less mass than the oxygen produced and, in some cases, can be used to support other surface infrastructure elements (e.g., power). The second is deployment of cargo in advance of the crew, in some cases, years before the crew arrives. The most significant example of how this aspect of the ConOps can be leveraged is the option to predeploy the MAV with the
ISRU equipment. This results in a significant reduction in mass launched from Earth and time on the surface can be used to make ascent propellant timed in such a way that the MAV is fully loaded with propellant when the crew arrives in a separate lander.

With this background, the first capability deployed for these surface missions is transportation to return the crew to orbit, that is the MAV. The assumption of a small (i.e., two person) crew for a short surface stay as the first surface mission in the EMC, and option exists to land this crew in a fully fueled MAV, and in so doing defer the use of ISRU, or to predeploy the MAV with ISRU systems before the first crew arrives on a separate lander. The two options have implications for the size of the lander needed and was part of the overall assessment being described here. The impacts of choosing one of these options is discussed in Section 6, Results.

The second capability deployed is power sufficient to support the next mission in the campaign. This is followed by habitation, which could be in the form of a fixed surface habitat or a small pressurized mobility system (typically an option limited to the first short stay mission). The balance of the capabilities (i.e., mobility, robotics, science, etc.) is delivered with no driving priority other than the mass and volume available on landers arriving for any particular surface mission. However, the entry, descent, and landing (EDL), described next, does require that the systems associated with these capabilities be grouped together in such a way that the EDL system can operate within its defined flight parameters (such as ballistic coefficient, center of gravity, etc.). This could mean that some surface systems or associated cargo (e.g., spares) could be sent prior to the mission in which they will be used.

\section{SySTEMS AND ELEMENT CONCEPTS}

To complete this assessment, specific mass and volume estimates for the capabilities just described must be specific in sufficient detail. Once again, work carried out by DOT was used as the basis for many of the systems assumed to satisfy the capability described [5]. Because trade studies being conducted for the in-space transportation used to deliver this surface infrastructure, several different landers, distinguished by the delivered payload mass capability, were developed for this assessment. The characteristics of these landers are discussed next before moving on to specific surface infrastructure systems and elements.

\section{Mars Lander Definition}

A Mars lander is defined as the combination of elements and systems that arrive at Mars. This definition is convenient at the architectural analysis level by clearly delineating the mass that the transportation systems must deliver to Mars. Figure 5.1 is a graphical depiction of the elements and systems that make up a Mars lander. Similar to the Russian matryoshka nested dolls, each element or system contains a "payload" consisting of other elements or 
systems. This analogy is quite useful in decomposing the operational, functional, and interface requirements during each phase of the mission. As previously introduced, the payload delivered to the Mars surface defines the required capabilities of the entry, descent, and landing systems.

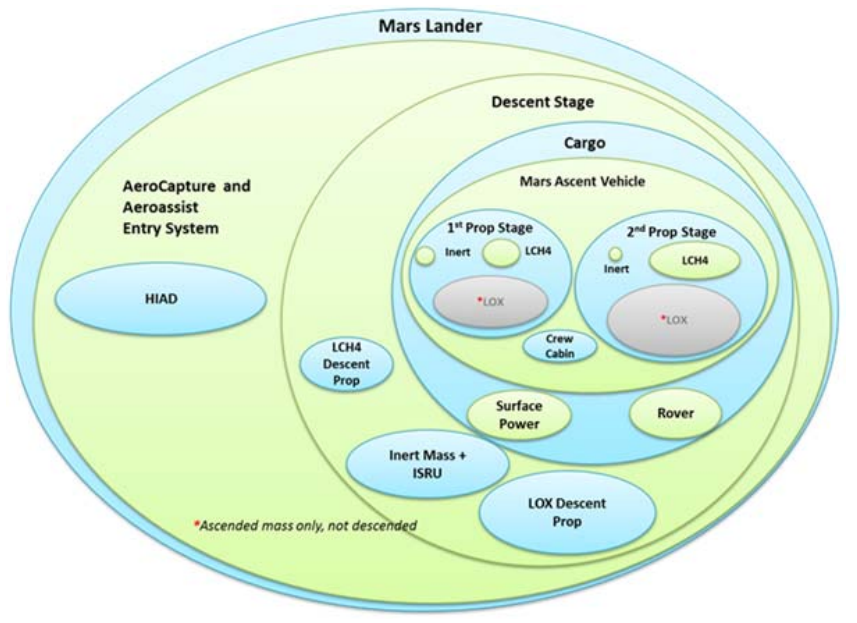

Figure 5.1. Elements and Systems of a Mars Lander

Figure 5.2 summarizes some of the key characteristics of the landers evaluated during the EMC.

\begin{tabular}{|l|c|c|c|}
\hline \multicolumn{4}{|c|}{ Key Lander Characteristics } \\
\hline Payload delivered to Mars Surface (t) & 18 & 27 & 40 \\
\hline MAV+LCH4+ISPP (t) & 18 & 18 & 18 \\
\hline Landed Mass (t) & 25.5 & 36.2 & 51.6 \\
\hline Arrival Mass (t) & 40.8 & 55.7 & 77.8 \\
\hline HIAD Diameter (m) & 16.1 & 18.8 & 23 \\
\hline Net Thrust (kN)/No. of Engines & $600 / 6$ & $800 / 8$ & $1,200 / 6$ \\
\hline Initial T/W & 2 & 2 & 2 \\
\hline Minimum Throttle (\%) & 15 & 15 & 15 \\
\hline
\end{tabular}

Figure 5.2. Key Mars Lander Characteristics

\section{Aerocapture, Entry, Descent, \& Landing (EDL) Description}

Landing on Mars is more difficult than landing on Earth's moon because of the higher gravity and the presence of an atmosphere. While the Mars atmosphere is very thin, it is still sufficient to generate significant heating on an entering body. However it is not sufficient to enable landing with only aerodynamic decelerators for the larger masses needed to support human missions. The largest payload landed on Mars to date is the Mars Science Laboratory, with a mass of approximately $900 \mathrm{~kg}$. Landing much larger payloads requires alternative approaches. A 2010 NASA Technical Memorandum documents the results of a study that evaluated alternative techniques for landing payload masses up to 40t [6]. The approaches with the lowest Mars arrival mass were the concepts that use aerodynamic decelerators until the system is at supersonic speeds with Mach number in the range of 2.5 to 3.0. The aerodynamic system then separates, the Mars Descent Module rocket engines are started, and spacecraft makes the powered descent, final approach, and landing.
A primary design assumption governing the EDL concept is that the entry, descent, and landing concept is common for all landers, both landers with only cargo and those with crew members on-board. Since the EDL is a very high risk aspect of the mission, this governing assumption provides demonstrated reliability with cargo missions prior to use with crew members.

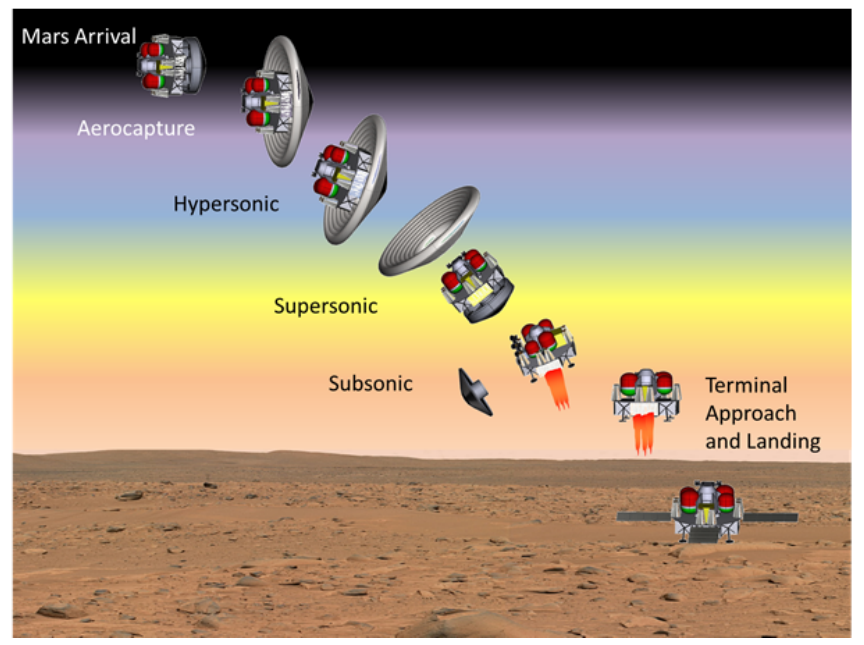

Figure 5.3. Entry and Landing Sequence of Events

\section{Aerocapture and Aeroassist Entry System}

The in-space Mars transportation analysis evaluated propulsive and aerocapture for Mars orbit insertion (MOI) and in conjunction with the EDL analysis, the EMC decided to place the MOI function on the Mars lander. Cargo landers can aerocapture into a Mars orbit and then transition directly to Mars entry, descent, and landing. However, the lander for the crew is delivered to Mars as a cargo element, but must be placed into a 1 Sol $(250 \mathrm{~km}$ x 33,500km) elliptical orbit and wait for the crew to arrive, up to 2 years later. In this concept of operations, the thermal protection systems will see a heating environment during the aerocapture maneuver when the vehicle enters the Mars atmosphere at an altitude of $40 \mathrm{~km}$ to provide sufficient aerodynamic drag to capture into a Mars orbit. An orbital correction propulsive burn is then performed to achieve the desired 1 Sol orbit. The technical implication is that the thermal protection system is exposed to significant heating and is then followed by a long duration exposure in the cold, deep space Mar orbital environment while waiting on the crew. This places additional technical challenges on the aerodynamic decelerator system, however multiple options exist to address this challenge and the associated mass implications are relatively well understood.

Multiple EDL concepts exist for Mars aerodynamic deceleration, however the only systems that integrate with the transportation options under consideration use deployable decelerations, which include Hypersonic Inflatable Aerodynamic Decelerator (HIAD) and the Adaptive Deployable Entry and Placement Technology (ADEPT). The HIAD and ADEPT provide similar performance and both appear to be viable solutions, but the 
detailed performance analysis and configuration studies have focused on the HIAD concept for the EMC and other recent work.

The HIAD concept is shown in Figure 5.4, and includes two primary components, a rigid nosecone heat shield similar to other heat shields used for Mars entry. However to increase the aerodynamic drag area, a flexible thermal protection system blanket is inflated to extend the conical section to the desired area and length to diameter ratio. The HIAD is inflated prior to the aerocapture maneuver and prior to entry into the Mars atmosphere. The HIAD slows the lander to a Mach number of approximately 3.0 at an altitude of $5 \mathrm{~km}$ to $7 \mathrm{~km}$ and then separates in a transition to the powered descent phase. This transition occurs in 7.5 seconds, where the inflatable decelerator slides to the back and away from the lander and the rigid heat shield is separated propulsively away from the MDM as the descent main engines are started.

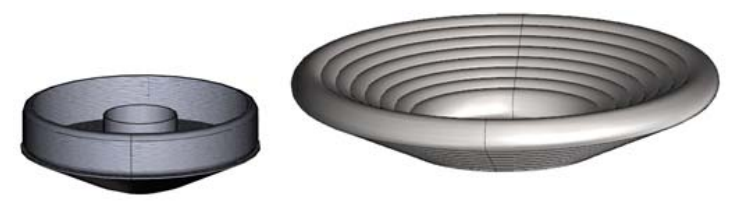

Figure 5.4. Hypersonic Inflatable Aerodynamic Decelerator

\section{Mars Descent Module}

The Mars Descent Module (MDM) is designed as a flatbed lander, as seen in Figure 5.5. Many conceptual design studies have been conducted on landers for human missions and no single optimum solution exists. It has been found that flatbed style landers provide more packaging flexibility for accommodating the different payload manifests, if the concept does not place undue burden on an offloading system. The concept developed for the EMC relies upon the use of multiple lower thrust rocket engines and multiple distributed propellant tanks than have been use in previous Mars lander architectures.

The rocket engines start while the vehicle is descending supersonically at a Mach number of approximately 2.5 to 3.0. This flight regime has been nicknamed Supersonic Retropropulsion (SRP) to describe the interaction of the supersonic rocket engine exhaust meeting the 'oncoming' supersonic Mars atmosphere. The primary technical concerns are associated with the engine start transient and the quasi-steady state flowfield generating an induced aerothermodynamic flowfield effecting vehicle stability or requiring additional vehicle protection systems. The induced environment due to the interaction of the rocket engine exhaust plumes and the supersonic shock interaction with the atmosphere can create aerodynamic forces and localized heating or icing and is an extremely complicated problem to analyze. Once the engines are at full thrust, the thrust greatly exceeds the aerodynamic forces, so that controllability is not anticipated to be a significant concern. While concern has been expressed about the ability to ignite and start the rocket engines when the nozzles are facing an oncoming Mach 3 supersonic Mars atmosphere, the total dynamic pressure inside the combustion chamber at engine ignition will be less at 0.75 psia, and rocket engines routinely start on earth's surface at $14.7 \mathrm{psia}$, so this issue is not a technical challenge.

In the current performance modeling, the rocket engines are sized to provide an initial thrust to weight of approximately 2.0 and requires a minimum total throttle to $15 \%$ power level at landing. The rocket engines sized for the MDM are the same engine as used on the Mars Ascent Vehicle and provides programmatic benefit by reducing the number of main engine developments. This minimum power level can be achieved by uniformly throttling all of the engines or by selectively shutting down engines. The liquid oxygen and liquid methane propellants will be maintained using a cryogenic fluid management system (CFM) consisting of broad area cooling with $90 \mathrm{~K}$ cyrocoolers and other CFM devices. The same cryocooler system on the MDM will supply $90 \mathrm{~K}$ helium to the broad area cooling system on the Mars Ascent Vehicle, providing thermal management for the methane fuel in the tanks during the cruise to Mars and to both propellants while on the surface of Mars.

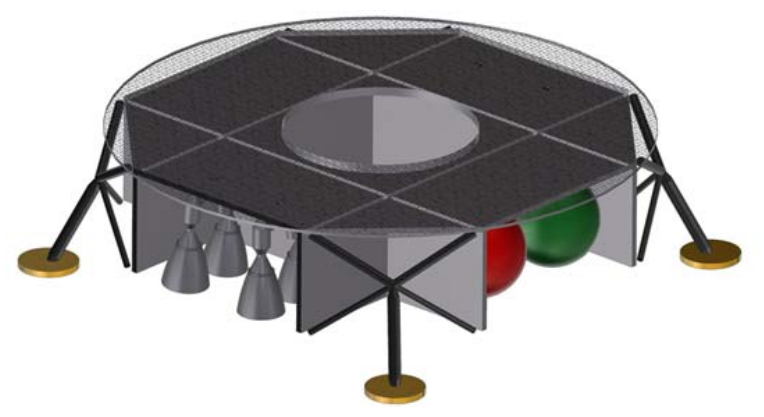

Figure 5.5. Mars Descent Module

\section{Mars Ascent Vehicle}

The Mars Ascent Vehicle (MAV) returns the crew to Mars orbit for rendezvous with the crew return vehicle. The crew return vehicle is assumed, based upon previous analysis [7] to be in a 1 Sol elliptical orbit. While this orbit increases the MAV's propellant requirement, it is a better optimization of the total mass delivered to Mars and other Mars orbit operations. The MAV is designed as a minimum function vehicle to return the crew to the Mars orbit and is designed to support 4 crew members for 43 hours, which includes contingency time for the orbital transfer maneuvers. The MAV is designed with a two-stage to orbit propulsion system. The second stage of the MAV uses a single $100 \mathrm{kN}$ LOX/LCH4 pump-fed rocket engine with a specific impulse of 360 sec. The first stage of the MAV uses 3 of the same engines and separates from the MAV and its second stage during ascent to a $250 \mathrm{~km}$ circular orbit. The second stage performs the remainder of circular orbit ascent and the transfer to the 1 Sol elliptical orbit and rendezvous with earth return vehicle. 
The MAV is the single largest indivisible payload and sets the minimum mass for the MDM. The MAV lands with liquid methane fuel in its tanks. The liquid oxygen is generated by the in-situ resource utilization (ISRU) system to produce oxygen from the Mars carbon dioxide atmosphere, a process called in-situ propellant production (ISPP). As discussed previously, propellant transfer approaches were considered during the EMC analysis cycle, but this approach was selected for the final performance analysis and packaging studies. The ISPP system will reside on the Mars descent module and produce the liquid oxygen for transfer to the MAV oxidizer tanks.
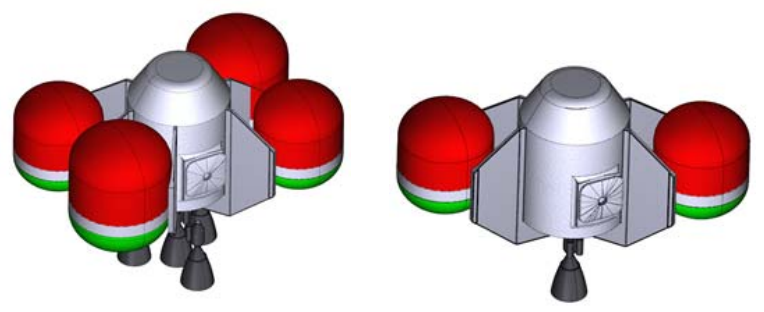

Figure 5.6. Two-Stage to Orbit Mars Ascent Vehicle

\section{Surface Power and ISRU Propellant Production}

Previous Lunar and Mars architecture studies have considered fission surface power systems (FSP) with the nominal size of $40 \mathrm{kWe}$ based on the required surface operation demands. For a the Mars lander that uses ISPP, approximately $40 \mathrm{kWe}$ power is required to produce, liquefy, and maintain it in its required cryogenic condition until needed for Mars ascent. Studies during the EMC evaluated the use of multiple smaller FSPs in lieu of a single large system, and while no exact decision was made to select a smaller system there are several benefits to adopting a lower power system. The Mars Lander packaging studies arbitrarily decided to use, eight (8) 5kWe FSP were assumed. Figure (5.x) shows the effect of alternate power system sizes that produce a total of $40 \mathrm{kWe}$ power.

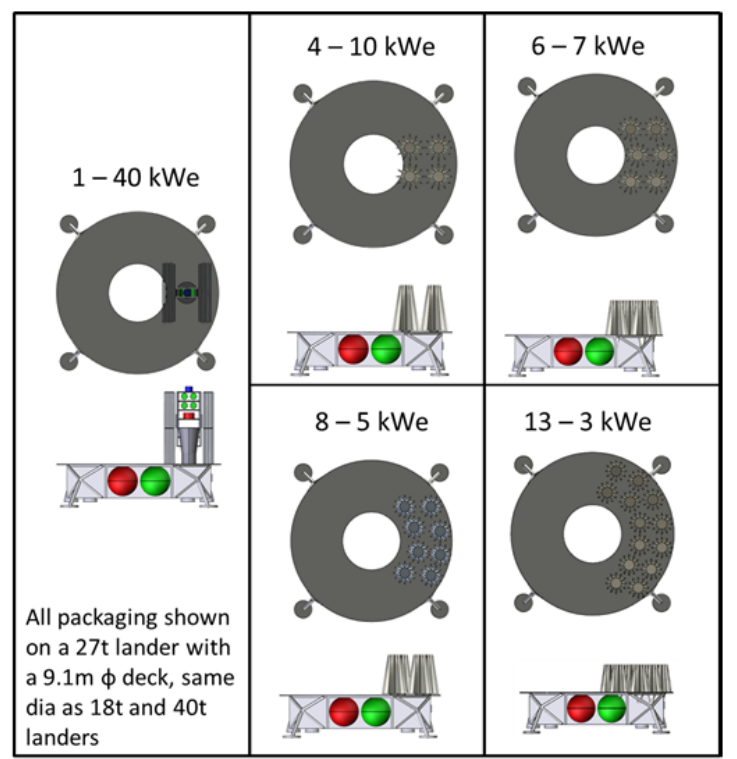

Figure 5.7. Packaging of Alternative Fission Power System Sizes

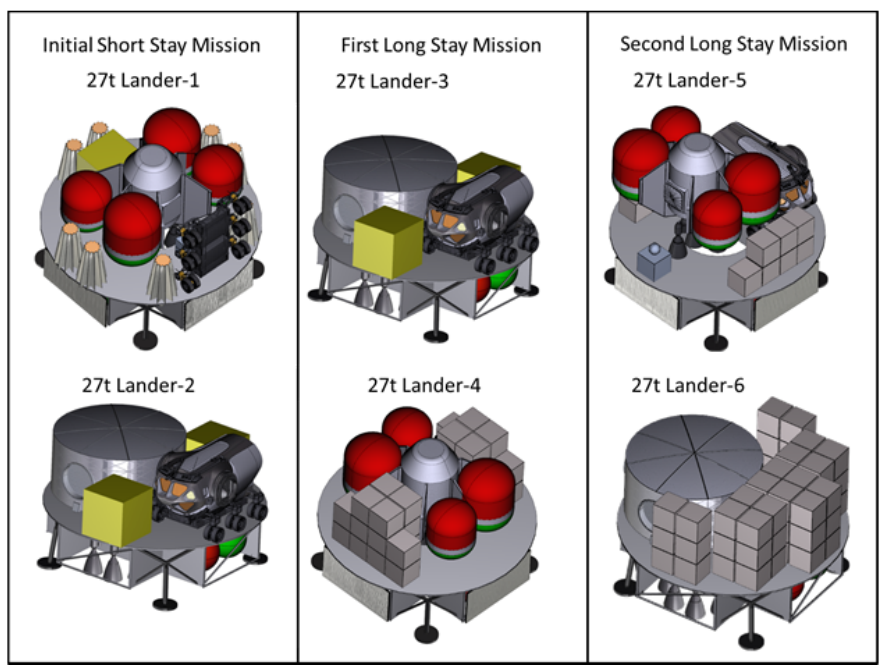

Figure 5.8. Entry and Landing Procedure

(summary)

\section{Surface Elements}

As identified in Section 3, notional elements were identified that would provide the needed functions for the seven capability categories. Table 5.1 provides a further description of each of these elements. Rough volume and power estimates of these elements were then used to define representative manifests for each lander payload option evaluated - 18t, 27t and $40 \mathrm{t}$. 
Table 5.1. Surface Element Descriptions

\begin{tabular}{|c|c|c|c|}
\hline \multirow[t]{7}{*}{ Habitation } & $\begin{array}{l}\text { Surface } \\
\text { Habitation } \\
\text { (4/500 day } \\
\text { monolithic) }\end{array}$ & & $\begin{array}{l}\text { - } \quad \text { All habitation subsystems necessary to support a crew of } 4 \text { for up to } 500 \text { sols } \\
\text { - } \quad \text { This system would be a single monolithic element. }\end{array}$ \\
\hline & $\begin{array}{l}\text { Surface Habitat } \\
\text { (4/500 day } \\
\text { modular) }\end{array}$ & & $\begin{array}{l}\text { - } \quad \text { All habitation subsystems necessary to support a crew of } 4 \text { for up to } 500 \text { sols. } \\
\text { This system would be made up of several separate elements that require integration on the surface } \\
\text { of Mars. }\end{array}$ \\
\hline & $\begin{array}{c}\text { Habitation } \\
\text { Augmentation }\end{array}$ & & $\begin{array}{l}\text { - A relatively small habitation system used to support up to } 4 \text { crew for short durations (e.g., up to } 30 \\
\text { sols) for applications such as providing additional habitable space during short duration surface } \\
\text { missions (augmenting MAV habitable space) or as an emergency shelter as backup to a primary } \\
\text { habitat } \\
\text { - } \quad \text { Life support subsystems are assumed to be open-loop } \\
\text { Several options exist as implementation examples of this element (e.g., a derivative of the EAM, a } \\
\text { derivative of the small pressurized rover cab, etc.) }\end{array}$ \\
\hline & $\begin{array}{l}\text { ECLSS/ } \\
\text { Maintenance } \\
\text { Hub }\end{array}$ & & $\begin{array}{l}\text { - A habitation system used to support a conops in which small pressurized rovers are assumed to } \\
\text { also serve as part of the fixed habitation infrastructure } \\
\text { In this scenario, this element houses large/heavy subsystems not needed during traverse in the } \\
\text { small pressurized rovers (e.g., closed-loop ECLSS, EVA suit maintenance, storage of crew } \\
\text { consumables for the entire surface mission, etc.) }\end{array}$ \\
\hline & $\begin{array}{l}\text { Consumables } \\
\text { for up to } \mathrm{N} \text { sols }\end{array}$ & & $\begin{array}{ll}\text { - } & \text { Dry food (and potable water) } \\
\text { - } & \text { Replacement clothing }\end{array}$ \\
\hline & $\begin{array}{l}\text { Spares and } \\
\text { Logistics }\end{array}$ & & $\begin{array}{l}\text { - } \quad \text { Spare parts and other logistical items needed to support operations for the entire duration of the } \\
\text { surface mission } \\
\text { - } \quad \text { Segregated into habitation, mobility, EVA, and power categories in order to track each type }\end{array}$ \\
\hline & Crew & & \\
\hline \multirow[t]{4}{*}{$\overline{\text { ISRU }}$} & $\begin{array}{l}\text { Demonstration } \\
\text { Unit } \\
\text { (Atmospheric) }\end{array}$ & & $\begin{array}{l}\text { - } \quad \text { System used to make liquid oxygen (LOX; for MAV propellant) from atmospheric CO2. } \\
\text { The purpose for this demonstration unit is to validate that technology chosen for a full-scale } \\
\text { system will operate in the Martian environment; the scale of the system should be such that the } \\
\text { growth path to a full-scale system does not require further demonstration units. }\end{array}$ \\
\hline & $\begin{array}{l}\text { Full Scale Unit } \\
\text { (Atmospheric) }\end{array}$ & & $\begin{array}{l}\text { - } \quad \text { System used to make liquid oxygen (for MAV propellant) from atmospheric CO2 } \\
\text { - The production capacity of this system should be such that all of the LOX needed for a MAV can } \\
\text { be generated within } 400 \text { (TBR) days. } \\
\text { - This system could be made up of a single monolithic unit or from several of the demonstration } \\
\text { scale systems ganged together. }\end{array}$ \\
\hline & LOX Tanker & & $\begin{array}{l}\text { - One or more tanks capable of storing LOX for extended periods of time and that can be moved for } \\
\text { distances of several thousand meters (the system that provides the mobility across the surface is } \\
\text { described separately below). }\end{array}$ \\
\hline & $\mathrm{CH}_{4}$ Tanker & & $\begin{array}{l}\text { - One or more tanks capable of storing liquid methane }\left(\mathrm{CH}_{4}\right) \text { for extended periods of time and that } \\
\text { can be moved for distances of several thousand meters (the system that provides the mobility } \\
\text { across the surface is described separately below). }\end{array}$ \\
\hline \multirow[t]{2}{*}{ Power } & $\begin{array}{l}\text { Demonstration } \\
\text { FSP Unit } \\
\text { (kilo-power) }\end{array}$ & & $\begin{array}{l}\text { - A fission-based power system used in conjunction with the ISRU Demonstration Unit } \\
\text { (Atmospheric) described previously } \\
\text { - The purpose for this demonstration unit is to validate that technology chosen for a full-scale } \\
\text { system will operate in the Martian environment; the scale of the system should be such that the } \\
\text { growth path to a full-scale system does not require further demonstration units }\end{array}$ \\
\hline & $\begin{array}{l}\text { Full Scale Unit } \\
\text { (kilo-power) }\end{array}$ & & $\begin{array}{l}\text { - A fission-based power system used in conjunction with the ISRU Full-Scale Unit (Atmospheric) } \\
\text { described previously } \\
\text { - The power capacity of this system should be such that the full-scale ISRU unit can generate all of } \\
\text { the LOX needed for a MAV within } 400 \text { (TBR) days. } \\
\text { - This system could be made up of a single monolithic unit or from several of the demonstration } \\
\text { scale systems ganged together. }\end{array}$ \\
\hline \multirow[t]{3}{*}{ EVA } & EVA + PLSS & & \\
\hline & LEA & & \\
\hline & Logistics & & \\
\hline \multirow[t]{4}{*}{ Mobility } & $\begin{array}{l}\text { Mobility System } \\
\text { to Reposition } \\
\text { Payload }\end{array}$ & & $\begin{array}{l}\text { - A system capable of moving relatively large payloads (several metric tons and/or large volumes) } \\
\text { over distances of several thousand kilometers. } \\
\text { The purpose of this element is to assist in surface site assembly (e.g., moving two habitation } \\
\text { elements to a site away from the lander that delivered them and positioning these elements so they } \\
\text { can be permanently connected) rather than to assist in long-range exploration traverses. }\end{array}$ \\
\hline & $\begin{array}{l}\text { Small } \\
\text { Unpressurized } \\
\text { Rover }\end{array}$ & & $\begin{array}{l}\text { - A small mobility system comparable to (but not necessarily a copy of) the Apollo Program's Lunar } \\
\text { Rover Vehicle used to transport EVA crew for relatively short distances when a small pressurized } \\
\text { rover is not required }\end{array}$ \\
\hline & $\begin{array}{l}\text { Small } \\
\text { Pressurized } \\
\text { Rover }\end{array}$ & & $\begin{array}{l}\text { - A self-contained rover capable of nominally supporting two crew for two week sorties between } \\
\text { resupply with range of } 100 \mathrm{~km} \text { (TBR) } \\
\text { In some conops options this vehicle's cabin can also be used to deliver the crew to the surface of } \\
\text { Mars and supporting those crew for several days as they readapt to the gravity environment }\end{array}$ \\
\hline & $\begin{array}{l}\text { Spares and } \\
\text { Logistics }\end{array}$ & & \\
\hline
\end{tabular}




\section{Table 5.1. Surface Element Descriptions}

\begin{tabular}{|c|c|c|c|c|}
\hline Robotics & Robotic Rover & - & $\begin{array}{l}\text { Small (approximately MER or MSL scale) robotic rover used initially for surface site } \\
\text { characterization/site selection and later to assist human crews with surface exploration tasks } \\
\text { At least one of these robotic rovers must be maintained in a "sterile" condition (as defined by the } \\
\text { Planetary Protection Officer) in order to enter "special regions" (as defined by the Planetary } \\
\text { Protection Officer) near the human landing site. }\end{array}$ \\
\hline Science & $\begin{array}{c}\text { Allocated } \\
\text { Payload }\end{array}$ & & $\bullet \begin{array}{l}\text { Other, smaller payload items (e.g., science experiments, small drilling equipment, etc.) that can } \\
\text { only be defined in general terms at this time and actual systems are likely to be scaled to fit } \\
\text { available mass and volume of the lander }\end{array}$ \\
\cline { 2 - 5 } & $\begin{array}{c}\text { Reconfigurable } \\
\text { Surface Science } \\
\text { Facility }\end{array}$ & $\begin{array}{l}\text { Reconfigurable space for surface science equipment } \\
\text { Provides utilities (e.g., power, thermal control, communications, etc.) for science and exploration } \\
\text { equipment used to support mission objectives } \\
\text { This facility is likely to be isolated from direct contact with crew (to minimize contamination of } \\
\text { experiments) and therefore is likely to support teleoperation of experiments by the crew. }\end{array}$ \\
\hline Transportation & $\begin{array}{c}\text { Mars Ascent } \\
\text { Vehicle }\end{array}$ & & \\
\hline
\end{tabular}




\section{RESULTS}

With these definitions in place, the remaining tasks in this assessment are to (1) determine discrete lander sizes based on delivering these surface infrastructure items in groupings that correspond to the previously discuss surface buildup sequence and (2) determine how many of these landers are required to deliver all of the surface infrastructure and support "Steady State" operations. As mentioned above, the results of these remaining assessments are key to illustrating the pros and cons of using many "small" landers compared to using a few "large" landers to establish and then support "Steady State" operations at a single surface site for the EMC.

\section{Discrete Landers Sizes}

As discussed briefly in Section 5 three lander sizes, defined by the payload mass they can deliver, have been looked at in detail during this assessment: 18, 27, and 40 metric tons. A fourth lander size, with a payload delivery capability of 15 metric tons, was also briefly considered and then discarded as will be explained below. A decision tree, shown in Figure 6.1, provides a visualization of the process that led to each of these landers sizes. This process involves factors discussed in all of the previously Sections: ground rules and assumptions chosen for this instance of the EMC, the concept of operations, the surface infrastructure delivery sequence, and the systems or elements that make up the components of the surface infrastructure.

This process began with an examination of all of the payload elements that were to be delivered by the landers. This examination was driven by a desire to identify those payload elements that could not be reasonably subdivided among multiple landers. Identifying this largest indivisible payload element would be one means of defining the minimum payload capacity needed by the lander. As shown on the left side of Figure 6.1, largest indivisible payload element was identified as the MAV. Other payloads were either a smaller mass or, for elements such as the habitat or power system, had implementation options that divided these elements into modular components that could be delivered separately and then assembled on the surface. The MAV itself could be divided into its inert components (i.e., tanks, engines, crew cab, etc.) and propellants. The three mass values shown in the mass table became key values driving the payload sizes that were the outcome of this assessment.

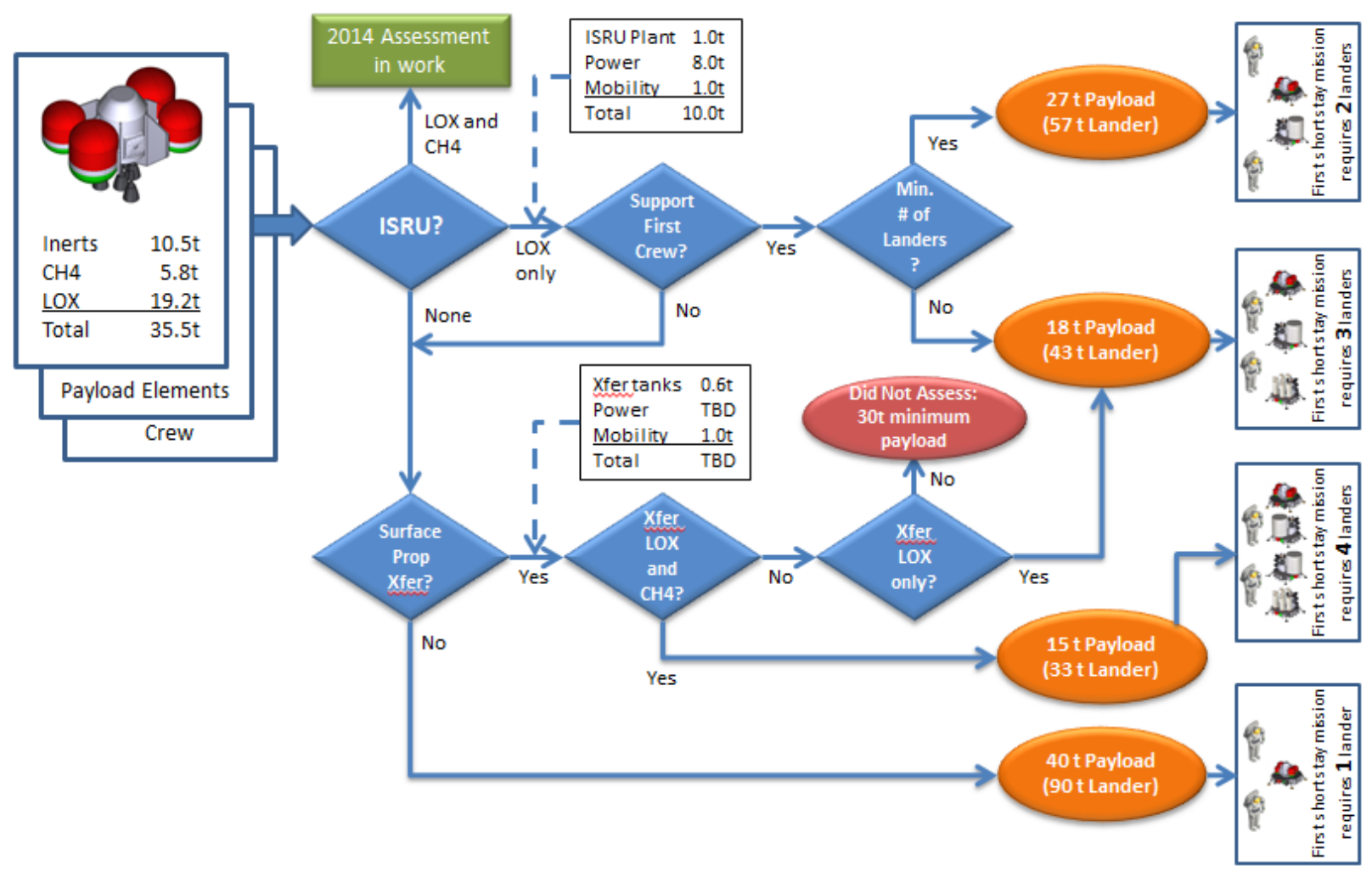

Figure 6.1. Lander Payload Capability Decision Tree 
The first decision point in this assessment process involved ISRU. Three possible choices were possible for this decision point: (1) do not use ISRU (this conflicts with one of the original assumptions for this assessment but was included to understand its implications), (2) use ISRU to make only liquid oxygen (LOX) for the MAV, and (3) use ISRU to make both LOX and liquid methane (LCH4 or just $\mathrm{CH} 4)$ for the MAV.

Information to support the third option was not available for this assessment due to a parallel assessment taking place to understand the scope and implementation details of this option.

Following the first ISRU decision path leads to the next operational decision: whether or not to include a capability to separately deliver LOX and LCH4 to the surface and then load these into the MAV. If transferring propellant while on the surface is not allowed then the MAV must be delivered with all LOX and LCH4 on board, a vehicle with a delivered mass of almost 36 metric tons. Other components needed to keep the MAV and these cryogenic propellant ready for the crew departure would raise the required payload mass above this level - the outcome shown at the bottom right of Figure 6.1. A lander with this capacity could deliver the first crew of two for the assumed initial short stay mission, which led to the total payload mass of 40 metric tons.

If propellant transfer is allowed on the surface then at a minimum additional capability to move this propellant from the lander delivering it to the MAV is required. There will also be a power requirement to maintain these MAV propellants at the proper cryogenic temperature until they are transferred to the MAV. The magnitude of this power requirement depends on a number of specific implementation assumptions that could not be assessed during this study. The mass associated with these additional capabilities are indicated in the small table along this decision path.

The next decision point along this path involves which propellants are delivered separately from the MAV. The "Yes" branch indicates delivering and transferring (on the surface) both LOX and LCH4. When the previously mentioned transfer systems and tankage to deliver the LOX and $\mathrm{CH} 4$ are taken into account along with the inert MAV, a lander with a payload capability of 15 metric tons satisfies all of the MAV delivery requirements with the least number of landers (i.e., three landers for just this element).

If only one of the propellants are delivered to the surface for transfer (i.e., the "No" branch out of the "Xfer LOX and LCH4" decision point) then the last decision on this path is whether LOX or LCH4 are transferred. The "No" branch from this decision point indicates that only LCH4 is delivered to the surface separately from the MAV. This means that the MAV is delivered with its LOX propellant onboard resulting in a payload mass of almost 30 metric tons. This result was similar to other outcomes with fewer operational challenges so this branch was not assessed further. The "Yes" branch implies that the MAV is delivered to the surface with its LCH4 propellant onboard, a payload with a mass of almost 17 metric tons. Several other small system needed in various operational scenarios that occur along this branch results in a payload capability of 18 metric tons.

Returning to the ISRU decision point, the "LOX only" branch implies that ISRU systems and the power to support it must be added to the manifest of required systems that must be delivered along with the MAV. The mass associated with these additional capabilities are indicated in the small table along this decision path.

The next decision point along this path was mentioned briefly in Section 4 (Sequence of Surface Buildup): whether or not to deploy the ISRU capability with the first crew (i.e., the short stay mission) or defer this capability until the buildup for the "Steady State" capability. If a decision is made to defer the ISRU capability (the "No" branch) then the path returns to the "no ISRU" at all path and the results are as described above. The "Yes" branch leads to one final decision point: whether to minimize the number of landers used or to minimize the payload mass capability of each lander (part of the high-level comparison being evaluated as described in the Introduction). Minimizing the payload mass capability (the "No" branch of this decision point) implies that the MAV with its LOX onboard becomes the maximum single payload that must be delivered, leading to the 18 metric ton lander described above. The mass associated with the ISRU system and its power source (approximately $25 \mathrm{~kW}$ provided by a fission power system) were delivered by another lander. Minimizing the number of landers needed to deliver the MAV and ISRU capability implies that a single lander capable of delivering 27 metric tons (a 17 metric ton MAV with only the LCH4 onboard plus the 10 metric tons of ISRU systems) would be needed.

To summarize, a guiding set of assumptions along with estimates for systems needed to support the concept of operation made for this instance of the EMC were used to determine a set of discrete payload masses that must be delivered by the lander element. The factors that led to these discrete payload masses were assembled into a decision tree format to help illustrate the origin of these payload mass values.

\section{Number of Landers to Support "Steady State" Operations}

With this set of required lander payload capabilities established, the next step in this task is to determine how many of these landers are required to achieve the various operational stages of this instance of the EMC. To briefly review, the instance of the EMC evaluated here called for an initial surface mission carried out by a small (two-person) crew for up to 30 Sols. This would be followed by at least one additional surface mission to establish all of the surface infrastructure necessary for "Steady State" operations. The second mission was assumed to be carried out by a crew of 
four remaining on the surface for up to 500 Sols. Subsequent "Steady State" surface missions would also be carried out by a crew of four staying on the surface for up to 500 Sols. To address a programmatic question, results were developed comparing an "early” introduction of ISRU (i.e., on the first "short stay" mission) for MAV propellant with a "late" introduction (i.e., on the second and subsequent "long stay" missions). Figure 6.2 illustrates the results of these analyses - for each of the three campaign phases and for the assumed ISRU introduction point - for each of the four landers identified previously.

For each campaign phase, the elements needed were identified and descriptions (including mass and volume) from Table 5.1 were assembled into manifests that could be carried by each lander type. As mentioned above, all of the systems or cargo elements in Table 5.1 had a unit mass less than the MAV or could be divided into quantities small enough to be carried by these landers. In many cases items such as crew consumables, spare parts, maintenance and repair items, etc., were assumed to be packaged in such a way that they could be distributed among several of the landers. This allowed the manifest for any particular lander to be made up of larger fixed mass items, such as the small pressurized rovers, and sufficient quantities of these smaller items to bring the total delivered payload mass up to the capacity of the lander. This is how the EDL system's requirement to maintain its flight characteristics within narrow bounds for any delivered payload, as discussed in Section 4, was achieved.

In all cases, the crew arrived in the final lander of any particular campaign phase, which is illustrated in Figure 6.2 by an EVA-suited crew member icon.

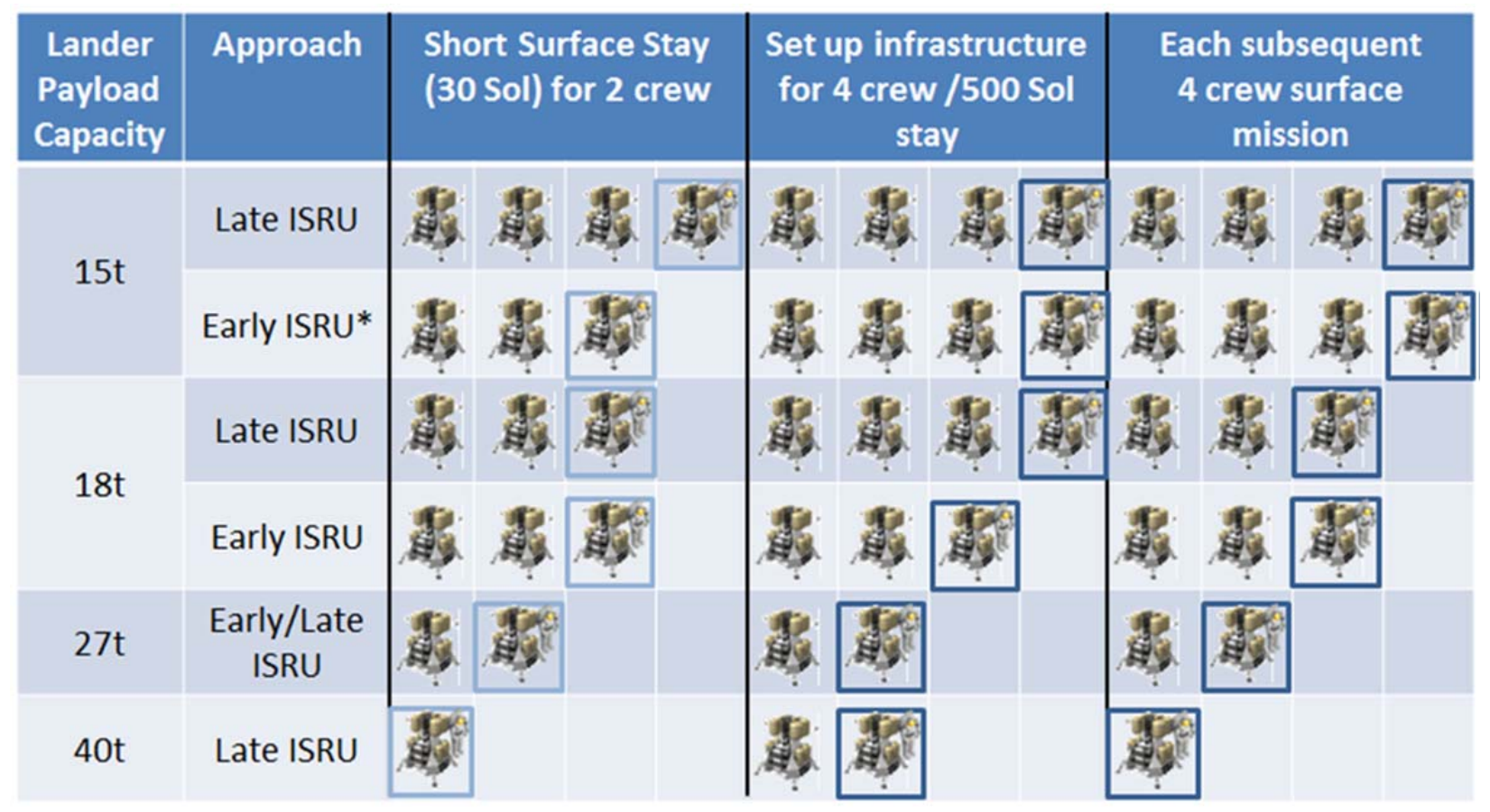

As can be seen in Figure 6.2, larger payload capability landers tends to reduce the number of landers needed to achieve each of the campaign phases. This is particularly interesting for a relatively small increase in payload capability from 15 metric tons to 18 metric tons. The benefit of a somewhat smaller lander compared with the cost of more landers and increased complexity of surface operations was a primary factor in eliminating the 15 metric ton lander option from further consideration in this assessment.

The "early" versus "late" deployment of ISRU was found to be somewhat beneficial for the 18 metric ton lander case, reducing the need for at least one lander across the campaign, but did not change the number of landers needed for the 27 metric ton case. The ISRU deployment options for the 40 metric ton case yielded a somewhat counter intuitive result. As indicated in Figure 6.1 decision tree, a 40 metric ton lander has sufficient capability to land a fully fueled MAV and could have been use in this mode for the first "short stay" mission. The other option of early ISRU deployment would require two landers - the first carrying the partially fueled MAV along with the ISRU equipment and associated power and the second carrying the crew in an appropriate habitable element. But as was shown in DRA 5.0 analyses, two 40 metric ton landers are sufficient to deliver all of the payload needed for a crew of four remaining on the surface for up to 500 Sols - far exceeding the objectives of the first surface mission assumed for this particular instance of the EMC.

* Also relies on propellant transfer on the surface 
Figure 6.2. Number of Landers Required to Complete EMC Objectives

Summarizing the observations made from these results: (1) the costs probably outweigh the benefits for a lander with a payload capability less than 18 metric tons, (2) early deployment of ISRU is somewhat beneficial for landers with 18 and 27 metric ton capabilities, and (3) late deployment of ISRU is probably a better strategy for a campaign using a lander with a 40 metric ton capability. These observations are being taken into account along with the results from other facets of the EMC to help make decisions for the overall approach to be taken.

\section{SUMMARY}

To summarize, NASA has an on-going need for assessments of reference mission or architecture options to provide meaningful characterizations to assist those making decisions regarding timing, objectives, and technologies for future human missions to Mars. This paper discussed results of one portion of these many assessments - the impact to surface operations resulting from (1) a choice to focus all surface infrastructure for human surface missions at a single site on Mars and (2) the pros and cons of building up this infrastructure using landers with different payload delivery capabilities. The "single site" portion of this assessment can be traced to the on-going evolution of NASA's Evolutionary Mars Campaign and the desire to explore different high-level goals and objectives to help understand the impact of these choices before committing to any of them. The "payload capability" portion of this assessment was carried out to examine several discrete lander sizes that were determined by certain operational considerations as well as the mass of various payload combinations. This assessment identified four discrete lander payload capabilities that could satisfy the objectives of this particular instance of the EMC: 15, 18, 27, and 40 metric tons.

Further examination of these options in light of EMC objectives and other operational considerations led to several observations that can be made from the results of this assessment: (1) the costs probably outweigh the benefits for a lander with a payload capability less than 18 metric tons, (2) early deployment of ISRU is somewhat beneficial for landers with 18 and 27 metric ton capabilities, and (3) late deployment of ISRU is probably a better strategy for a campaign using a lander with a 40 metric ton capability. These observations are being taken into account along with the results from other facets of the EMC to help make decisions for the overall approach to be taken.

\section{REFERENCES}

[1] citation for NASA Authorization Act of 2010 (in Section 1)

[2]Anon. (May 29, 2014). Pioneering Space: NASA's Next Steps on the Path to Mars. Copied from http://www.nasa.gov/sites/default/files/files/Pioneeringspace-final-052914b.pdf.

[3] Anon. (June 28, 2010). National Space Policy of the United States of America. Copied from: http://www.whitehouse.gov/sites/default/files/national_sp ace_policy_6-28-10.pdf

[4] B Drake (2009). Human Exploration of Mars: Design Reference Architecture 5.0. NASA/SP-2009-566

[5] citation for DOT 2013 final report (in Section 5)

[6] citation for a 2010 NASA Technical Memorandum documents the results of a study that evaluated alternative techniques for landing payload masses up to 40t (in Section 5)

[7] citation for previous study of the crew return vehicle (in Section 5) 


\section{BIOGRAPHY}

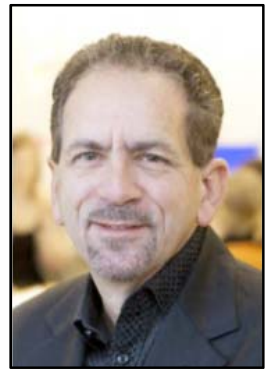

Larry Toups attained a Bachelor of Architecture Degree from the University of Houston. After practicing architecture, he received a Masters Degree in Space Architecture from the University of Houston, Sasakawa Institute for Space Architecture. From June 1988 - January 1994 he was a Senior Engineer with Lockheed Engineering and Sciences Company at Johnson Space Center. In this role, he provided technical support for JSC's New Initiatives Office in the area of Systems Engineering of habitats and planetary systems and contributed to numerous NASA studies. From 1998-2003, Mr. Toups assumed the role of Habitability Systems Lead in the ISS Vehicle Office. He is currently in the Exploration Mission Systems Office at Johnson Space Center.

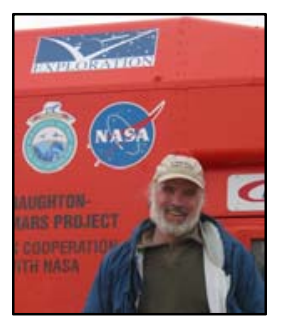

Stephen Hoffman received a B.S., M.S., and Ph.D. in Aeronautical and Astronautical Engineering from the University of Illinois in 1978, 1980, and 1984 respectively. Dr. Hoffman is a Senior Systems Engineer with 35 years of experience working in civilian space programs performing tasks involving program management, interplanetary mission planning, preliminary spacecraft design, orbit mechanics, and planetary analog missions. Dr. Hoffman is currently supporting the Exploration Missions and Systems Office at the NASA Johnson Space Center. He supports a variety of mission studies and concept assessments associated with human exploration beyond low Earth orbit for this office.

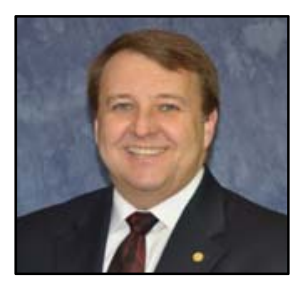

Kendall Brown received a B.S. in Mechanical Engineering from Oklahoma State University in 1985, a M.S. in Aeronautics and Astronautics from the University of Washington in 1991, and Ph.D. in Mechanical Engineering from the University of Alabama in Huntsville in 1996. He has been with NASA Marshall Space Flight Center (MSFC) since 2000 and spent most of that time as a liquid propellant rocket engine system engineer working on projects ranging from the Space Shuttle Main Engine, RS-83, RS83, TR-107, RL-10, and J-2X. He was the Propulsion Subsystem Lead for the Altair Lunar Lander and then the Deputy Project Manager at MSFC. He was the Chief Strategist for the congressional requested National Rocket Propulsion Strategy study. 
